\title{
Reorganization of Recurrent Layer 5 Corticospinal Networks Following Adult Motor Training
}

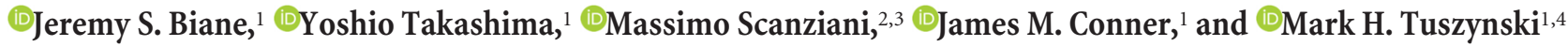 \\ Departments of ${ }^{1}$ Neurosciences, ${ }^{2}$ Neurobiology, University of California, San Diego, California 92093, ${ }^{3}$ Howard Hughes Medical Institute, San Diego, \\ California, 92093, and ${ }^{4}$ Veterans Administration Medical Center, San Diego, California 92161
}

Recurrent synaptic connections between neighboring neurons are a key feature of mammalian cortex, accounting for the vast majority of cortical inputs. Although computational models indicate that reorganization of recurrent connectivity is a primary driver of experiencedependent cortical tuning, the true biological features of recurrent network plasticity are not well identified. Indeed, whether rewiring of connections between cortical neurons occurs during behavioral training, as is widely predicted, remains unknown. Here, we probe M1 recurrent circuits following motor training in adult male rats and find robust synaptic reorganization among functionally related layer 5 neurons, resulting in a 2.5 -fold increase in recurrent connection probability. This reorganization is specific to the neuronal subpopulation most relevant for executing the trained motor skill, and behavioral performance was impaired following targeted molecular inhibition of this subpopulation. In contrast, recurrent connectivity is unaffected among neighboring layer 5 neurons largely unrelated to the trained behavior. Training-related corticospinal cells also express increased excitability following training. These findings establish the presence of selective modifications in recurrent cortical networks in adulthood following training.

Key words: cortical plasticity; motor cortex; motor learning; neural circuits; recurrent connectivity; synaptic plasticity

\section{Significance Statement}

Recurrent synaptic connections between neighboring neurons are characteristic of cortical architecture, and modifications to these circuits are thought to underlie in part learning in the adult brain. We now show that there are robust changes in recurrent connections in the rat motor cortex upon training on a novel motor task. Motor training results in a 2.5 -fold increase in recurrent connectivity, but only within the neuronal subpopulation most relevant for executing the new motor behavior; recurrent connectivity is unaffected among adjoining neurons that do not execute the trained behavior. These findings demonstrate selective reorganization of recurrent synaptic connections in the adult neocortex following novel motor experience, and illuminate fundamental properties of cortical function and plasticity.

\section{Introduction}

Within neocortex, local connections between neighboring neurons represent the predominant source of synaptic input (Binzegger et al., 2004; Douglas and Martin, 2004). During development, recurrent cortical networks undergo extensive reorganization, with connectivity becoming progressively biased toward functionally re-

Received Nov. 5, 2017; revised March 28, 2019; accepted April 1, 2019.

Author contributions: J.S.B., J.M.C., M.S., and M.H.T. designed research; J.S.B., Y.T., and J.M.C. performed research; J.S.B. analyzed data; J.S.B. wrote the first draft of the paper; J.S.B., J.M.C., M.S., and M.H.T. edited the paper; J.S.B., J.M.C., and M.H.T. wrote the paper.

This work was supported by National Institutes of Health Grant AG10435, the Kavli Foundation, the Veterans Administration, and the Dr. Miriam and Sheldon G. Adelson Medical Research Foundation. We thank Mingshan Xue, Dante Bartone, and Matthew 0'Sullivan for technical assistance; and Jennifer Dulin for artwork.

The authors declare no competing financial interests.

Correspondence should be addressed to Mark H. Tuszynski at mtuszynski@ucsd.edu.

J.S. Biane's present address: Department of Psychiatry, University of California, San Francisco, California.

J.M. Conner's present address: Salk Institute for Biological Studies, La Jolla, California.

M. Scanziani's present address: Howard Hughes Medical Institute, University of California, San Francisco, California.

https://doi.org/10.1523/JNEUROSCI.3442-17.2019

Copyright $\odot 2019$ the authors lated neuronal ensembles (Ko et al., 2013; Biane et al., 2015). In adulthood, recurrent connections are hypothesized to generate stable neural activity patterns (i.e., attractor states) from inputs that are often noisy and variable, accomplishing this transformation by amplifying inputs (Li et al., 2013a,b; Lien and Scanziani, 2013; Reinhold et al., 2015), restoring signals embedded in noise (Douglas and Martin, 2007), implementing "winner-take-all" processing of competing inputs (Douglas et al., 1995), and/or fostering sustained patterns of neural activity (Vogels et al., 2005). Accordingly, experience-dependent tuning of recurrent connectivity is thought to play a fundamental role in the stabilization of spatiotemporal activity patterns. In the context of skilled motor behavior, such stabilization of activity patterns accompanies training (Peters et al., 2014), and may in turn provide a means for automating complex motor sequences (Laje and Buonomano, 2013). Yet to date, in vivo data confirming the existence of modifications to recurrent connections during training are lacking. Consequently, it is unknown whether motor experience indeed generates reorganization of recurrent synaptic wir- 
ing between neighboring cortical cells, and whether such rewiring preferentially engages neuronal subpopulations most relevant to the trained behavior, as might be predicted.

To examine these questions, we leveraged the ability to identify subpopulations of corticospinal neurons associated with highly specific motor functions within the motor cortex (M1) of adult rats (Anderson et al., 2010; Morishima et al., 2011; Wang et al., 2011; Biane et al., 2015). Ex vivo whole-cell recordings were used to examine: (1) whether adult adaptations in recurrent connectivity accompany skilled motor training, and (2) whether any network modifications preferentially affect the neuronal subpopulation most relevant for controlling the trained motor skill. Our results demonstrate that recurrent connectivity is augmented following novel motor experience. This increase was specific to the neuronal subpopulation most relevant for the trained motor behavior, whereas neighboring neurons unrelated to the trained behavior exhibited no change in overall recurrent synaptic organization. Furthermore, intrinsic excitability is also selectively modified within the task-related subpopulation following training. We confirm that the projection-specific subpopulation displaying increased connectivity is necessary for performance of the skilled motor behavior by globally inhibiting this subpopulation during task performance. These findings demonstrate that recurrent connections show robust and selective reorganization in the adult neocortex following novel motor experience.

\section{Materials and Methods}

Neuronal labeling. All procedures and animal care adhered to American Association for the Accreditation of Laboratory Animal Care and institutional guidelines for experimental animal health, safety, and comfort. Male F344 rats, weighing $\sim 85 \mathrm{~g}$ (approximately postnatal day P35), were anesthetized with a mixture $(2 \mathrm{ml} / \mathrm{kg})$ containing ketamine $(25 \mathrm{mg} / \mathrm{ml})$, xylazine $(1.3 \mathrm{mg} / \mathrm{ml})$, and acepromazine $(0.25 \mathrm{mg} / \mathrm{ml})$. In rats, the C8 spinal cord segment contains lower motor neurons that activate muscles controlling distal forelimb movements required for grasping (McKenna et al., 2000; Tosolini and Morris, 2012). Lower motor neuron pools located in the C4 spinal segment are associated with control of proximal forelimb, shoulder, and neck musculature (Callister et al., 1987; McKenna et al., 2000; Tosolini and Morris, 2012). To label corticospinal neurons projecting to the $\mathrm{C} 8$ cervical spinal cord, the overlying dura between $\mathrm{C} 7$ and T1 was resected and a glass micropipette (tip $<40 \mu \mathrm{m})$ containing red or green fluorescent latex microspheres (Lumafluor) was inserted into the dorsal horn of spinal cord (depth $0.75 \mathrm{~mm}, 0.55 \mathrm{~mm}$ lateral to midline). Using a Picospritzer II (General Valve), $\sim 350 \mathrm{nl}$ of fluorescent latex microspheres was injected into each side of the spinal cord. To label corticospinal neurons projecting to the upper cervical spinal cord, the same procedure was repeated between $\mathrm{C} 3$ and $\mathrm{C} 4$ spinal vertebra, using a different colored dye (green or red) than that used for C8 injections. In all cases, tracer diffusion was assessed postmortem in $50 \mu \mathrm{m}$ coronal slices of the spinal cord. Animals with tracer diffusion into the dorsal columns were excluded from further study. In total, 12 animals were excluded, whereas 137 were included for analysis. Because the exact tracer (red or green) injected into $\mathrm{C} 4$ or $\mathrm{C} 8$ was counterbalanced and varied from animal to animal, the experimenter was blind to the specific projection target of a labeled cortical cell during recording.

Histology. Histological procedures followed those previously described (Biane et al., 2014). Animals were deeply anesthetized and transcardially perfused with $250 \mathrm{ml}$ cold PBS, pH 7.4, followed by $250 \mathrm{ml}$ of cold $4 \%$ PFA in $0.1 \mathrm{~m}$ phosphate buffer. Brains were extracted, postfixed overnight in the same fixative, then cryoprotected in $0.1 \mathrm{M}$ phosphate buffer containing $30 \%$ sucrose for at least $72 \mathrm{~h}$ at $4^{\circ} \mathrm{C}$. Coronal sections $(50 \mu \mathrm{m})$ were cut on a freezing sliding microtome and stored in tissue cryoprotectant solution (TCS) at $4^{\circ} \mathrm{C}$ until processed for immunohistochemistry.

To immunolabel hM4D(Gi)-mCherry, free-floating sections were washed in TBS and permeabilized with $0.25 \%$ Triton X-100. Nonspecific labeling was blocked with $5 \%$ donkey serum. Sections were incubated for $72 \mathrm{~h}$ at $4^{\circ} \mathrm{C}$ in in rabbit anti-RFP antibody (Abcam; catalog \#AB34771; RRID:AB_777699) diluted 1:2500 in TBS, 0.25\% Triton X-100, and 5\% donkey serum. Following primary antibody incubation, sections were incubated in biotin-conjugated donkey anti-rabbit IgG (1:200; Vector Laboratories). Amplification of mCherry signal was achieved via tyramide signal amplification (PerkinElmer), after which sections were washed in TBS and incubated in AlexaFluor-594-conjugated streptavidin (Invitrogen) diluted 1:200 for $3 \mathrm{~h}$ at $4^{\circ} \mathrm{C}$. Sections were again washed, mounted on glass slides, and coverslipped in Fluoromount-G (Southern Biotechnology).

Slice preparation. One to five days following completion of training, rats were anesthetized and perfused for $3 \mathrm{~min}$ with ice-cold, oxygenated, modified sucrose ACSF containing the following (in mM): $75 \mathrm{NaCl}, 2.5$ $\mathrm{KCl}, 3.3 \mathrm{MgSO}_{4}, 0.5 \mathrm{CaCl}_{2}, 1 \mathrm{NaH}_{2} \mathrm{PO}_{4}, 26.2 \mathrm{NaHCO}_{3}, 22$ glucose, 52.6 sucrose, 10 HEPES, 10 choline chloride, 1 pyruvate, 1 L-ascorbic acid ( $\sim 300 \mathrm{mOsml}, \mathrm{pH} 7.4)$. The brain was rapidly dissected, and 330- $\mu \mathrm{m}-$ thick slices spanning the motor cortex were cut at $15^{\circ}$ anterior to the mid-coronal plane to match the apical dendrite projection pattern of layer 5 corticospinal neurons. Cortical slices were cut and collected in ice-cold, oxygenated, modified sucrose ACSF. Slices were transferred to an interface chamber containing the same modified sucrose ACSF solution and incubated at $34^{\circ} \mathrm{C}$ for $30 \mathrm{~min}$. Slices were then held at room temperature $\left(23^{\circ} \mathrm{C}\right)$ in the interface chamber for at least $40 \mathrm{~min}$ before initiating recordings. Recordings were made in a submersion-type recording chamber and perfused with oxygenated ACSF containing the following (in mM): $119 \mathrm{NaCl}$, $2.5 \mathrm{KCl}, 1.3 \mathrm{MgCl}_{2}, 2.5 \mathrm{CaCl}_{2}, 1.3 \mathrm{NaH}_{2} \mathrm{PO}_{4}, 26.0 \mathrm{NaHCO}_{3}, 20$ glucose $(\sim 300 \mathrm{mOsml})$ at $23^{\circ} \mathrm{C}$ at a rate of $2-3 \mathrm{ml} / \mathrm{min}$. Postnatal age at time of recording was $56 \pm 2 \mathrm{~d}$, an age where the motor system has fully matured (Markus and Petit, 1987; Biane et al., 2015).

\section{Experimental design and analysis}

Skilled grasp training. At approximate age P39, animals began skilled reach training as described previously (Conner et al., 2003, 2005, 2010). Briefly, animals were first acclimated to the experimenter and testing chamber for a total of $5 \mathrm{~d}$ before initiating reaching. Animals were weighed, and food restriction was initiated $2 \mathrm{~d}$ before initiating reaching. Animals were required to reach through a small opening to obtain a single $45 \mathrm{mg}$ sucrose pellet (Test Diets) located on an indented platform $\sim 2 \mathrm{~cm}$ beyond the reaching chamber. Reach training was performed across 10 consecutive days, and animals performed 40-60 reaching trials per day. A trial was defined as an extension of the forepaw beyond the chamber façade toward the pellet-containing platform. A successful trial was scored if animals successfully retrieved the pellet. Grasping accuracy was scored as the total number of successful trials divided by the total number of trials. To control for potential effects due to food restriction, handling, or exposure to a novel food (reward pellets), control animals were similarly food restricted, handled, spent an equal amount of time in the reaching chamber, and consumed an equal number of reward pellets as did reach-trained animals. However, controls were manually fed reward pellets with forceps, thus not allowing the animal to reach for or grasp reward pellets.

Grid walk. Foot falls were measured as animals walked on a $1600 \mathrm{~cm}^{2}$ wire grid containing $6 \mathrm{~cm}^{2}$ openings, in $6-8$ min test sessions captured on video (Grill et al., 1997). Forepaws were scored for the total number of foot placements (correctly positioning foot on wire mesh) and total number of foot falls (misplacement of foot resulting in the foot dropping below the grid). The number of placements and foot falls were summed to give the total number of steps. Percentage of foot falls was calculated by dividing the total number of foot falls by total number of steps.

Electrophysiology. All recordings were performed within the cortical hemisphere contralateral to the preferred reaching paw during training. In the case of untrained animals, the hemisphere recorded was selected randomly. The experimenter conducting slice recordings was blinded to the training status of the animal being recorded. Neurons were selected based on emission spectra (red or green, reflecting tracers injected at either the C8 or C4 spinal segment) and then visualized under infrared differential interference contrast videomicroscopy (Olympus BX-51 scope and Rolera XR digital camera). Whole-cell voltage and current-clamp re- 
cordings were made at room temperature using pulled patch pipettes (4-7 $\mathrm{M} \Omega$ ) filled with internal solution containing the following (in $\mathrm{mM}$ ): 150 K-gluconate, $1.5 \mathrm{MgCl}_{2}$, 5.0 HEPES, 1 EGTA, 10 phosphocreatine, 2.0 ATP, and 0.3 GTP. Postsynaptic data were analyzed exclusively from cells with a resting membrane potential $\leq-55 \mathrm{mV}$, with drift $<6 \mathrm{mV}$ over the entire recording period, with access resistance $\leq 35 \mathrm{M} \Omega$, with the ability to evoke multiple spikes with $>60 \mathrm{mV}$ peak amplitude from threshold, and with a holding current of $>-500 \mathrm{pA}$ to keep the cell at a holding potential of -65 $\mathrm{mV}$. Basic membrane properties are reported only for cells whose holding current was $>-150 \mathrm{pA}$. Series resistance was not compensated but was continuously monitored via negative voltage steps. In a minority of cell pairs $(\sim 15 \%)$, the "presynaptic" neuron was fired in cell-attached mode and was not reciprocally tested for synaptic input.

Synaptic connectivity. Whole-cell patch-clamp recordings were obtained using Multiclamp 700B patch amplifiers (Molecular Devices) and data analyzed using pClamp 10 software (Molecular Devices). To determine connectivity among C4- and C8-projecting cell populations, simultaneous whole-cell recordings were made in groups of 2-4 retrogradely labeled cells. The distribution of C4- and C8-projecting cells, which are almost entirely intermingled across the forelimb region of primary motor cortex (Wang et al., 2011), enabled all types of paired recordings to be obtained within a single field $(\mathrm{C} 4 \rightarrow \mathrm{C} 4, \mathrm{C} 8 \rightarrow \mathrm{C} 8, \mathrm{C} 4 \rightarrow \mathrm{C} 8$, and $\mathrm{C} 8 \rightarrow \mathrm{C} 4)$. Data were collected from cells $>30 \mu \mathrm{m}$ below the slice surface (mean \pm $\mathrm{SD}=67 \pm 26 \mu \mathrm{m}$ ). Connectivity was determined by evoking action potentials in a presynaptic cell while monitoring responses in postsynaptic cells held at $-65 \mathrm{mV}$ in voltage clamp. Presynaptic action potentials were evoked by a $7 \mathrm{~ms}$ depolarizing current injection of $2 \mathrm{nA}$. Individual sweeps were separated by $5 \mathrm{~s}$.

The responses to $30-50$ evoked action potentials were measured for each paired recording. Connectivity was inferred if the average peak response in the postsynaptic cell was $>2 \mathrm{SD}$ above noise. In connected cell pairs, failure rate was calculated as the percentage of single trials in which the postsynaptic peak current was $<2$ SD below baseline current noise. All traces were manually inspected for signal consistency, including monotonic rise and decay and reliable onset latency. Postsynaptic response amplitude was calculated as the averaged current over a $1.5 \mathrm{~ms}$ time window of peak response current compared with baseline, which was defined as the average current in a $5 \mathrm{~ms}$ window before presynaptic firing. Response potency was calculated using only traces where a postsynaptic response was detected (failures omitted). Response latency was measured from the peak of the presynaptic spike to the onset of EPSC (onset was defined as $10 \%$ of peak signal). Rise time was calculated as the time between $20 \%$ and $80 \%$ peak EPSC amplitude. During offline processing, a minority $(\sim 10 \%)$ of connections were detected with the postsynaptic cell in current clamp, with no voltage-clamp traces obtained. Postsynaptic properties of potency, rise time, and decay time for these cells are not included in the dataset. For paired pulse analysis, the peak response to each pulse was averaged over all trials (i.e., failures were not omitted), and the average response of the first response was divided by that to second pulse. To preserve the relative differences in magnitude for ratios $>1$ and $<1$, the logarithm of each ratio was used for statistical comparisons.

Reciprocal analysis. In a randomly connected network with connection probability $p_{c}$ and total number of reciprocally tested cell pairs $N$, the expected number of unconnected pairs is $N\left(1-p_{c}\right)^{2}$. The expected number of unidirectionally connected pairs is $2 N \times p_{c}\left(1-p_{c}\right)$, and the expected number of reciprocally connected pairs is $N \times p_{c}{ }^{2}$ (Song et al., 2005). To test for overrepresentation of reciprocally connected cell pairs, 10,000 iterations were simulated for Monte Carlo analysis.

Intrinsic excitability. To characterize basic membrane properties, a series of hyperpolarizing and depolarizing current steps were applied for $500 \mathrm{~ms}$ in $10-50 \mathrm{pA}$ increments at $5 \mathrm{~s}$ intervals. Rheobase was determined as the lowest level of depolarizing current required to evoke a spike. Action potential spike measurements were taken from the first action potential on the first sweep to reach threshold. Spike threshold was defined at the time point where the first derivative $\geq 10 \mathrm{mV} / \mathrm{ms}$. Spike height was measured as the overall peak membrane voltage, and half-width was measured at the half-amplitude of the action potential. Input resistance $\left(\mathrm{R}_{\text {in }}\right)$ was determined from the slope of the linear regression taken through the voltage-current relationship in the hyperpolarizing range.
Maximum afterhyperpolarization (AHP) was calculated as the maximum hyperpolarization relative to action potential threshold following depolarizing current injection that evoked a single spike. Additionally, AHP was alternatively calculated in cells for which a $300 \mathrm{pA}$ depolarizing current delivered for $500 \mathrm{~ms}$ evoked at least 4 spikes. Reported $p$ values reflect the main effect of training for a two-way ANOVA (IV1 = training; IV2 = number of spikes elicited by current injection).

Neuronal inhibition. Neonatal rats (age P3) received pressure injections $(0.5 \mu \mathrm{l} / \mathrm{min})$ of a viral mixture of adeno-associated virus (AAV) serotypes 2, 5, and 8, all containing an hSyn-DIO-hM4D(Gi)-mCherry construct (University of North Carolina Vector Core). Anesthesia was induced via hypothermia. Injections were targeted to the caudal forelimb region of M1, where C4- and C8-projecting neurons are spatially intermingled (Wang et al., 2011). For the L2-projecting group, injections were targeted to the hindlimb region of M1. Animals received two, $300 \mathrm{nl}$ injections per hemisphere, at a depth of $700 \mu \mathrm{m}$. Subsequent spinal cord injections of $400 \mathrm{nl}$ of AAV9-CaMKII-CRE (University of Pennsylvania Vector Core) at age $\sim$ P35 followed surgical procedures as outlined for neuronal labeling. Spinal cord injections at L2 required a laminectomy of the T12 vertebra. An additional, positive control group received four 300 $\mathrm{nl}$ injections/hemisphere of a non-CRE-dependent AAV8 hSynhM4D(Gi)-mCherry (University of North Carolina Vector Core) directly into the caudal forelimb region of $\mathrm{M} 1$ at age $20 \mathrm{~d}$. Injections were made at 2 depths/site at 1400 and $600 \mu \mathrm{m}$. In total, 23 animals were included for these experiments $(\mathrm{C} 8=9, \mathrm{C} 4=7, \mathrm{~L} 2=5, \mathrm{M} 1=2)$. For neuronal inhibition experiments, intraperitoneal injections containing either clozapine- $n$-oxide (CNO, $5 \mathrm{mg} / \mathrm{kg}$; Tocris Bioscience) or saline vehicle were delivered $45 \mathrm{~min}$ before testing. Animals were subsequently tested as normal (see above).

Experimental design and statistical analysis. In total, 160 animals (average age $56 \pm 2 \mathrm{~d}$, all male) were included: 137 for connectivity examinations and 23 for cell inhibition. The large number of animals for the connectivity study was necessary given the difficulty in obtaining paired recordings in adult animals, combined with the low connectivity rate among neurons. An average of 24.6 connections were tested for each animal.

Statistical comparisons were performed using JMP software, version 11.0 (SAS Institute). Comparisons of connection frequency were made using Fisher's exact test. Unless otherwise noted, pairwise comparisons were made using Student's $t$ test or Wilcoxon test for normal and nonnormally distributed data. Normality was assessed by applying a fitted normal to each dataset and assessing goodness of fit. Significant $p$ value was set at 0.05 . In-text data values are presented as the mean $\pm S D$.

\section{Results}

\section{Identification of task-related cortical neurons}

We used previously established methods for identifying individual neurons of the motor cortex that are associated with performance of a skilled grasping behavior (Wang et al., 2011, 2016). Labeling of individual corticospinal neurons of layer 5 motor cortex (M1) that control either the proximal or distal forelimb can be achieved by injection of different colored retrograde latex microspheres into dorsal gray matter of cervical level 8 (C8) spinal segment that controls distal forelimb muscles for skilled grasping, or cervical level 4 (C4) spinal segment that controls proximal muscles for shoulder movements (Callister et al., 1987; McKenna et al., 2000; Wang et al., 2011; Tosolini and Morris, 2012). We previously demonstrated that this approach identifies a specific subpopulation of layer 5 neurons within M1 that exhibit increased spine density and augmented thalamocortical (TC) input as a function of skilled motor grasp training; these modifications are restricted to the $\mathrm{C} 8$-projecting motor neuronal population that is activated when performing a skilled grasping task (Wang et al., 2011; Biane et al., 2016). In contrast, C4projecting motor neurons in layer 5 , which control upper forelimb musculature but not the distal digits involved in performing 
Table 1. Excitatory postsynaptic response properties ${ }^{a}$

\begin{tabular}{|c|c|c|c|c|c|c|c|c|}
\hline & \multicolumn{2}{|l|}{$\mathrm{C} 4 \rightarrow \mathrm{C} 4$} & \multicolumn{2}{|l|}{$\mathrm{C} 8 \rightarrow \mathrm{C} 8$} & \multicolumn{2}{|l|}{$\mathrm{C} 4 \rightarrow \mathrm{C} 8$} & \multicolumn{2}{|l|}{$\mathrm{C} 8 \rightarrow \mathrm{C} 4$} \\
\hline & Untrained & Trained & Untrained & Trained & Untrained & Trained & Untrained & Trained \\
\hline Failure rate & $\begin{array}{l}0.51 \pm 0.26 \\
(n=22)\end{array}$ & $\begin{array}{l}0.45 \pm 0.17 \\
(n=12) p=0.48\end{array}$ & $\begin{array}{l}0.33 \pm 0.19 \\
(n=12)\end{array}$ & $\begin{array}{l}0.45 \pm 0.21 \\
(n=32) p=0.1\end{array}$ & $\begin{array}{l}0.48 \pm 0.27 \\
(n=14)\end{array}$ & $\begin{array}{l}0.39 \pm 0.25 \\
(n=10) p=0.38\end{array}$ & $\begin{array}{l}0.31 \pm 0.26 \\
(n=14)\end{array}$ & $\begin{array}{l}0.43 \pm 0.23 \\
(n=13) p=0.21\end{array}$ \\
\hline Onset latency (ms) & $\begin{array}{l}3.1 \pm 1.4 \\
(n=22)\end{array}$ & $\begin{array}{l}2.6 \pm 1.2 \\
(n=12) p=0.39\end{array}$ & $\begin{array}{l}2.4 \pm 0.8 \\
(n=12)\end{array}$ & $\begin{array}{l}2.4 \pm 0.8 \\
(n=32) p=0.9\end{array}$ & $\begin{array}{l}2.9 \pm 1.7 \\
(n=14)\end{array}$ & $\begin{array}{l}3.0 \pm 1.1 \\
(n=10) p=0.97\end{array}$ & $\begin{array}{l}2.4 \pm 0.8 \\
(n=14)\end{array}$ & $\begin{array}{l}2.9 \pm 1 \\
(n=13) p=0.14\end{array}$ \\
\hline Median potency (pA) & $\begin{array}{l}-6.2 \pm 6.9 \\
(n=20)\end{array}$ & $\begin{array}{l}-6.9 \pm 2.6 \\
(n=11) p=0.81\end{array}$ & $\begin{array}{l}-8.2 \pm 1.8 \\
(n=12)\end{array}$ & $\begin{array}{l}-6.5 \pm 5.5 \\
(n=32) p=0.22\end{array}$ & $\begin{array}{l}-5.1 \pm 5.7 \\
(n=13)\end{array}$ & $\begin{array}{l}-7.5 \pm 3.2 \\
(n=9) p=0.32\end{array}$ & $\begin{array}{l}-8.1 \pm 3.6 \\
(n=12)\end{array}$ & $\begin{array}{l}-5.9 \pm 4 \\
(n=12) p=0.09\end{array}$ \\
\hline Coefficient of variation & $\begin{array}{l}1 \pm 1.3 \\
(n=20)\end{array}$ & $\begin{array}{l}1 \pm 0.5 \\
(n=11) p=0.36\end{array}$ & $\begin{array}{l}0.9 \pm 0.7 \\
(n=12)\end{array}$ & $\begin{array}{l}0.9 \pm 0.8 \\
(n=32) p=0.91\end{array}$ & $\begin{array}{l}1.3 \pm 0.9 \\
(n=13)\end{array}$ & $\begin{array}{l}0.9 \pm 1.1 \\
(n=9) p=0.53\end{array}$ & $\begin{array}{l}0.7 \pm 1.7 \\
(n=12)\end{array}$ & $\begin{array}{l}1.0 \pm 0.9 \\
(n=12) p=0.63\end{array}$ \\
\hline Rise time (ms) & $\begin{array}{l}2.1 \pm 0.7 \\
(n=20)\end{array}$ & $\begin{array}{l}2.4 \pm 0.9 \\
(n=11) p=0.21\end{array}$ & $\begin{array}{l}2.1 \pm 0.6 \\
(n=12)\end{array}$ & $\begin{array}{l}1.9 \pm 0.6 \\
(n=32) p=0.42\end{array}$ & $\begin{array}{l}1.9 \pm 0.7 \\
(n=13)\end{array}$ & $\begin{array}{l}2.4 \pm 0.9 \\
(n=9) p=0.2\end{array}$ & $\begin{array}{l}2.1 \pm 0.6 \\
(n=12)\end{array}$ & $\begin{array}{l}2.4 \pm 1.6 \\
(n=12) p=0.6\end{array}$ \\
\hline Decay time (ms) & $\begin{array}{l}17.6 \pm 11.5 \\
(n=20)\end{array}$ & $\begin{array}{l}19 \pm 9.6 \\
(n=11) p=0.74\end{array}$ & $\begin{array}{l}17.3 \pm 5.5 \\
(n=12)\end{array}$ & $\begin{array}{l}14.9 \pm 4.9 \\
(n=32) p=0.22\end{array}$ & $\begin{array}{l}15.9 \pm 6.9 \\
(n=13)\end{array}$ & $\begin{array}{l}18 \pm 5.7 \\
(n=9) p=0.48\end{array}$ & $\begin{array}{l}15 \pm 6.2 \\
(n=12)\end{array}$ & $\begin{array}{l}13.2 \pm 6 \\
(n=12) p=0.42\end{array}$ \\
\hline
\end{tabular}

${ }^{a}$ Data are mean \pm SD. $p$ values reflect comparisons of trained versus untrained conditions within each cell-pair group.

skilled grasping, undergo no changes in structure or thalamic input following training.

\section{Recurrent connection probability is increased specifically within the task-related subpopulation of layer 5 neurons following training}

To investigate whether recurrent synaptic circuitry is altered by motor experience in adulthood, and whether these changes are specific for cells most relevant to the trained behavior, we examined interconnectivity across neurons with distinct relevance for the skilled forelimb grasping task. Rats first received injections of different retrograde tracers into the $\mathrm{C} 8$ and $\mathrm{C} 4$ spinal segments to label subsets of layer 5 corticospinal neurons that were relevant (C8-projecting) or not essential (C4-projecting) for skilled grasping (Fig. $1 A$ ). Following an $8 \mathrm{~d}$ recovery period, rats underwent skilled grasp training over 10 consecutive days (Fig. $1 B, C$ ), during which animals learned to refine control of distal forelimb musculature to retrieve a remote sugar pellet with a single forepaw (Conner et al., 2003; Kargo and Nitz, 2003; Gharbawie and Whishaw, 2006). During training, performance improved from a baseline of $38 \pm 13 \%$ grasping success to $72 \pm 10 \%$ on the final day of training (mean $\pm \mathrm{SD}$; repeated-measures ANOVA, $F_{(9,1111)}=1102, p<0.001$; Fig. $\left.1 C\right)$. Within $5 \mathrm{~d}$ of completing training, cortical slices of M1 were prepared and up to four C8and C4-projecting corticospinal neurons were targeted for simultaneous whole-cell recordings (Fig. $1 D, E$ ). Targeting these unique subpopulations of layer 5 neurons for paired intercellular recordings in cortical slices enabled the identification of circuitlevel changes associated with training, including potential modifications in recurrent connectivity, synaptic properties, and intrinsic physiological properties. In total, 3366 connections were tested in 137 animals of average age $56 \pm 2 \mathrm{~d}$.

Skilled-grasp training resulted in a 2.5 -fold increase in recurrent connectivity among the task-related subnetwork of layer 5 neurons projecting to $\mathrm{C} 8(\mathrm{C} 8 \rightarrow \mathrm{C} 8$; Fisher's exact test, $p=0.003$; Fig. $1 F)$. In contrast, recurrent connectivity among layer 5 neurons associated with control of more proximal forelimb musculature unnecessary for grasping was unchanged $(\mathrm{C} 4 \rightarrow \mathrm{C} 4 ; p=0.721$; Fig. $1 F)$. This increase in recurrent connectivity among C8-projecting neurons was highly specific, as excitatory connections across different subpopulations of neurons $(\mathrm{C} 8 \rightarrow \mathrm{C} 4$ or $\mathrm{C} 4 \rightarrow \mathrm{C} 8)$ did not change significantly $(p=0.323$ and $p=1.0$, respectively; Fig. $1 F)$. Thus, motor training is associated with a selective increase in recurrent connectivity among task-related pyramidal neurons.
These results were not driven by depth of recorded cells from the slice surface or the distance between cells (Fig. 1G). Overall, total intersomatic distance had no effect on connection probability at distances of $0-100 \mu \mathrm{m}$ (logistic analysis, $p=0.893$ ). At distances $>100 \mu \mathrm{m}$, the rate of excitatory connectivity diminished with distance $(p<0.001)$. Further, consistent with previous reports (Song et al., 2005; Fino and Yuste, 2011), connection probability was not significantly related to cell depth below the slice surface (logistic analysis, $p=0.499$ ).

As has been previously shown for layer 5 neurons in cortex (Song et al., 2005; Perin et al., 2011), reciprocally (i.e., bidirectionally) connected cell pairs were overrepresented compared with that expected from a randomly connected network (overall $p_{\mathrm{c}}=0.038$; expected rate of reciprocal connectivity $=p_{\mathrm{c}}^{2}=$ 0.0015 ; actual rate $=0.0115$; Monte Carlo simulation test for overrepresentation, $p<0.001)$. The rate of reciprocal connectivity did not differ between all cell pair groups (Pearson's $\chi^{2}$ test $=$ $0.681, p=0.878$ ). Additionally, the rate of reciprocal connectivity between $\mathrm{C} 8$-projecting cell pairs did not change following training (untrained $=0.01$, trained $=0.015$; Fisher's exact test, $p=0.531$ ), suggesting that new functional connections following training were not biased toward forming reciprocal associations, nor did they preferentially connect cell pairs with a preexisting, unidirectional connection before learning.

\section{Recurrent synaptic properties are largely unchanged following skilled motor training}

It has been previously shown that TC synapses onto C8-projecting corticospinal neurons undergo potentiation following motor skill training (Biane et al., 2016). To test whether experience-dependent potentiation also occurs at recurrent synapses, we examined synaptic transmission among recurrent $\mathrm{C} 8 \rightarrow \mathrm{C} 8$ networks before and after training. However, unitary EPSC (uEPSC) amplitude, potency, failure rate, coefficient of variation, and paired-pulse ratio showed little change as a function of training (failure rate: binomial distribution test; all others: Wilcoxon rank sum test; Fig. 2; for exact $p$ values, see Table 1). Notably, synaptic properties displayed considerable variability in their values, particularly for uEPSC amplitude. We thus tested whether the distributions of $\mathrm{C} 8$ - $\mathrm{C} 8$ response amplitude differed across trained and untrained animals but found that these were not significantly different (Kolmogorov-Smirnov test, $p=0.797$ ). Furthermore, all remaining cell-pair groups $(\mathrm{C} 4 \rightarrow \mathrm{C} 4, \mathrm{C} 4 \rightarrow \mathrm{C} 8$, $\mathrm{C} 8 \rightarrow \mathrm{C} 4$ ) displayed no significant differences in recurrent synaptic properties after skilled grasp training (Table 1). These 


\begin{tabular}{|c|c|c|c|}
\hline $\begin{array}{c}\text { Retrograde } \\
\text { bead injection }\end{array}$ & Recovery & $\begin{array}{r}\text { Skilled-grasp training } \\
\text { Handling, food restriction }\end{array}$ & $\begin{array}{c}\text { Record from } \\
\text { M1 slices }\end{array}$ \\
\hline
\end{tabular}

〜P35 P36 - $38 \quad$ P39 - 54 P55 - 59

A

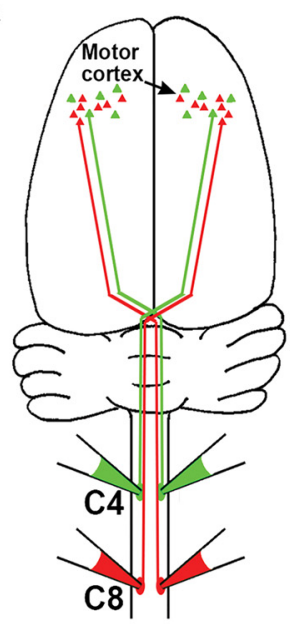

B

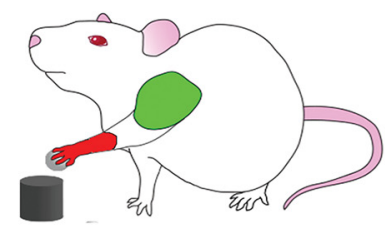

C

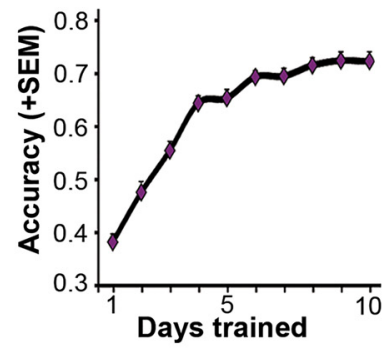

D

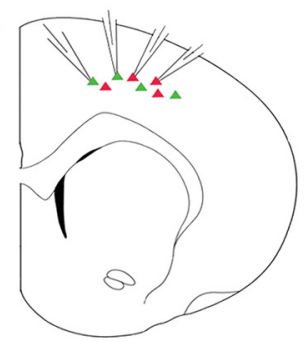

E

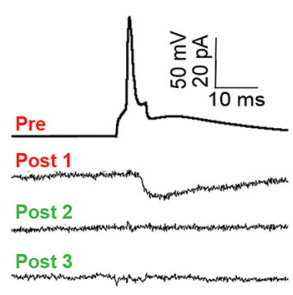

F

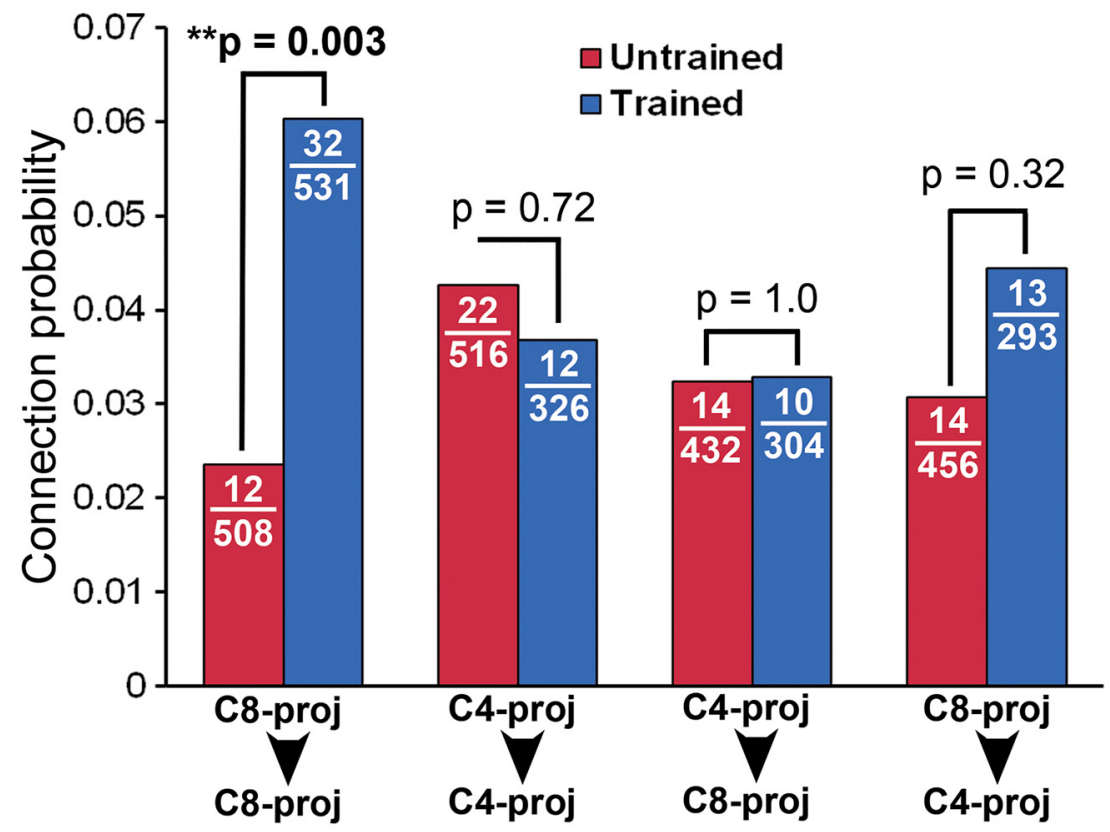

G
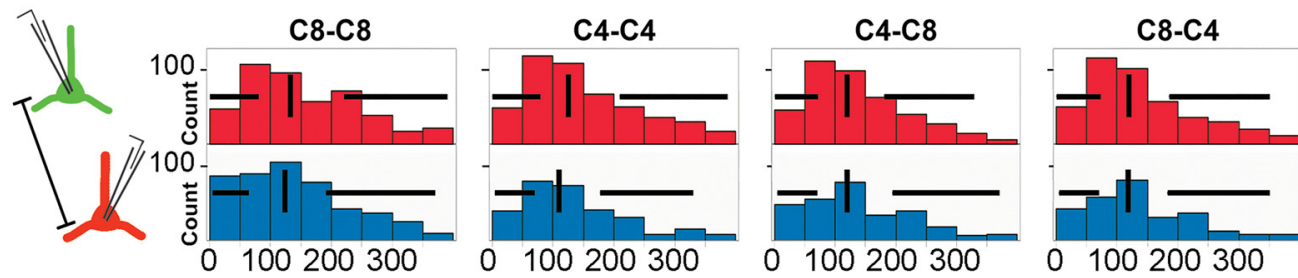

Intersomatic distance $(\mu \mathrm{m})$

Figure 1. Recurrent connectivity is selectively increased following skilled grasp training among the task-related, (8-projecting corticospinal subpopulation. Top, Experimental timeline. $\boldsymbol{A}$, Spinal cord cervical level 8 (C8) contains motor neurons that project to and control distal forelimb musculature, whereas level 4 controls proximal forelimb musculature, including neck and shoulder. At age $35 \mathrm{~d}$, injections of different colored retrograde tracers were made at C8 and C4. B, C, Following retrograde bead injection, animals were trained $10 \mathrm{~d}$ in the skilled grasp motor task, showing significant increases in grasping accuracy over this period. $D$, To assess synaptic connectivity, brain slices containing the forelimb area of M1 contralateral to the preferred grasping paw were prepared, and retrogradely labeled layer 5 corticospinal neurons were targeted for whole-cell patch-clamp recording. $\boldsymbol{E}$, Sample quadruple recording trace showing cell pairs that are (Pre-Post 1 ) or are not (Pre-Post 2,3) synaptically connected. $\boldsymbol{F}$, Following grasp training, there is a 2.5 -fold increase in interconnectivity among (8-projecting corticospinal (Figure legend continues.) 
A

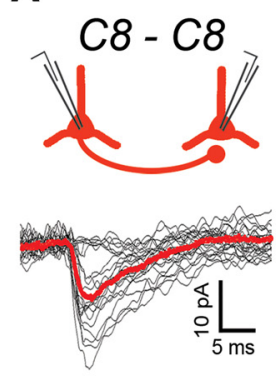

B

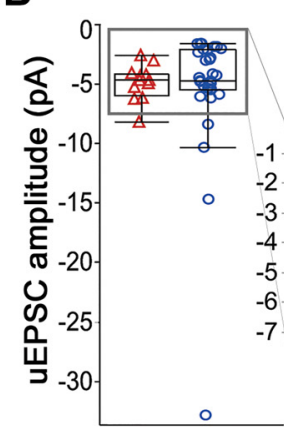

C

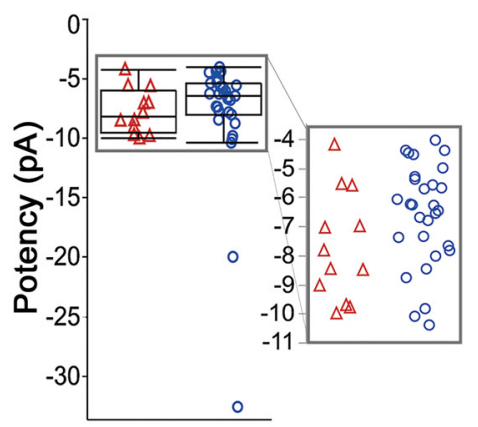

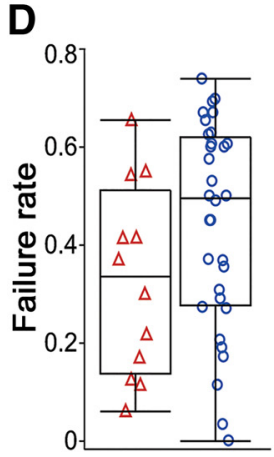

E

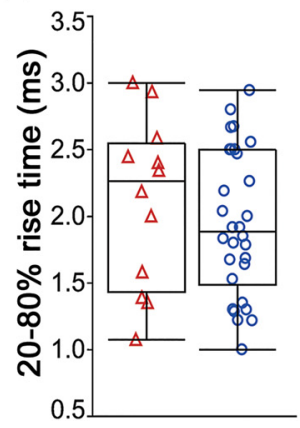

$\mathbf{F}$

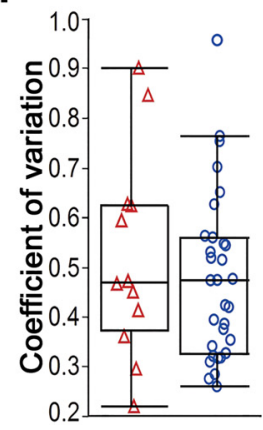

G

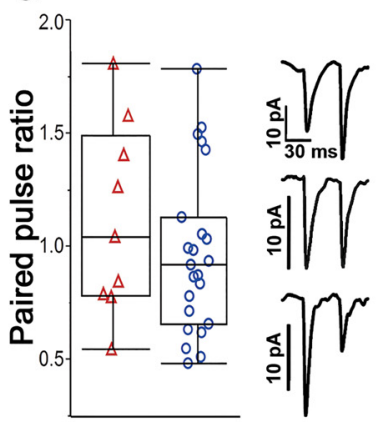

Figure 2. uEPSC response properties of C8-C8 cell pairs do not differ in trained and untrained animals. A, Synaptically connected C8-projecting cells and superimposed postsynaptic traces in response to single action potentials. Red trace represents cumulative average of all responses with failures removed (uEPSC potency). $\boldsymbol{B}-\boldsymbol{G}$, uEPSC response properties for synaptically connected C8-projecting neurons were highly variable and not significantly different between trained and untrained conditions. Box plots define quartiles (outliers omitted). $\boldsymbol{B}, \boldsymbol{C}$, Clustered data points are expanded for clarity.

results indicate that unitary synaptic inputs between corticospinal neurons are functionally similar before and after training. Consequently, distinct neural pathways (i.e., TC vs recurrent) exhibit specialized mechanisms of plasticity following motor experience.

\section{Intrinsic excitability is increased specifically within the task- related subpopulation following learning}

Previous studies have reported increases in neuronal excitability across more generalized cell populations as a consequence of novel experience (Disterhoft et al., 1986; Oh et al., 2003; Murphy et al., 2004). Based on these prior studies, we postulated that skilled forelimb grasp training also alters intrinsic excitability, and further hypothesized that excitation would be biased toward the trained, behaviorally relevant movement via augmented excitability within the C8-projecting network. Indeed, a significant increase in spiking in response to depolarizing current injection was observed in C8-projecting cells in trained versus untrained animals (repeated-measures ANOVA: $F_{(1,73)}=10.84, p=0.002$; Fig. $3 A$ ). A reduction of the AHP current was also observed in the C8-projecting population of trained animals $\left(t\right.$ test, $t_{(59)}=2.12$, $p=0.038$; Fig. $3 D, F)$. Reduced AHP current has been shown to

(Figure legend continued.) neurons (i.e., among the network of neurons that generate the skilled grasping behavior). In contrast, there is no change in connectivity within the (4projecting network that is uninvolved in skilled grasp performance. Further, across-network connectivity ( $4 \rightarrow C \mathrm{C}$ or $\mathrm{C} 8 \rightarrow \mathrm{C} 4)$ does not change significantly with skilled motor training. These findings indicate that changes in neuronal connectivity in response to new motor experience are specific to the trained network. $G$, Total intersomatic distance between the soma of recorded cell pairs did not differ between cell pair groups or training conditions. Vertical lines $=$ median; horizontal lines $=$ box plot whiskers. ${ }^{* *} p<0.01$. be associated with increased spiking (Faber and Sah, 2007), although AHP and spiking data in the current study were collected from distinct cells. Moreover, the rheobase trended toward a significant reduction in trained versus untrained C8-projecting cells (Wilcoxon Rank Sum test, $z=1.86, p=0.062$ ). C4-projecting cells, in marked contrast, exhibited no significant changes in AHP (Fig. $3 D, F$ ) or spike threshold (Wilcoxon Rank Sum test, $z=$ $0.88, p=0.373$ ) following training (Table 2). Accordingly, intrinsic spiking behavior in the $\mathrm{C} 4$-projecting subpopulation was unaffected by learning (repeated-measures ANOVA, $F_{(1,51)}=0.3$, $p=0.584$; Fig. $3 B$ ).

\section{Population-specific inhibition of C8-projecting cells}

\section{selectively impairs grasping accuracy}

To further corroborate the functional relevance of C8-projecting corticospinal neurons to skilled forelimb grasping, we used the designer receptor exclusively activated by designer drug (DREADD) inhibitory receptor system to reversibly inactivate these neurons during task performance. By way of a two-step Cre-combinatorial viral system (Fig. $4 A, B$ ), expression of the DREADD inhibitory receptor hM4D(Gi) (Urban and Roth, 2015) was selectively targeted to corticospinal neurons projecting to one of three spinal cord levels: $\mathrm{C} 8, \mathrm{C} 4$, or, as a negative control group, lumbar level 2 (L2), which is associated with control of the hindlimb (Callister et al., 1987; McKenna et al., 2000; Tosolini and Morris, 2012). Using this technique, DREADD expression was restricted to large pyramidal cells of layer 5 within the motor cortex, consistent with exclusive labeling of corticospinal neurons (Fig. 4B). Application of the DREADD ligand CNO $(7 \mu \mathrm{M}$ $\mathrm{CNO}$ ) to ex vivo slices containing hM4D(Gi)-expressing corticospinal neurons confirmed effective neuronal inhibition: neurons 
A

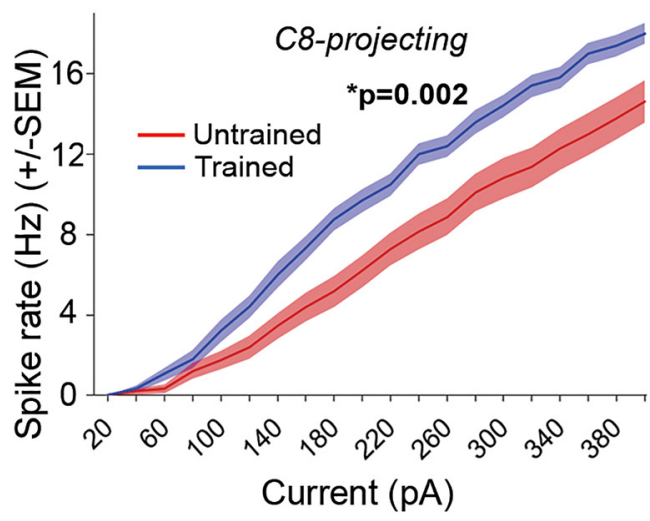

B

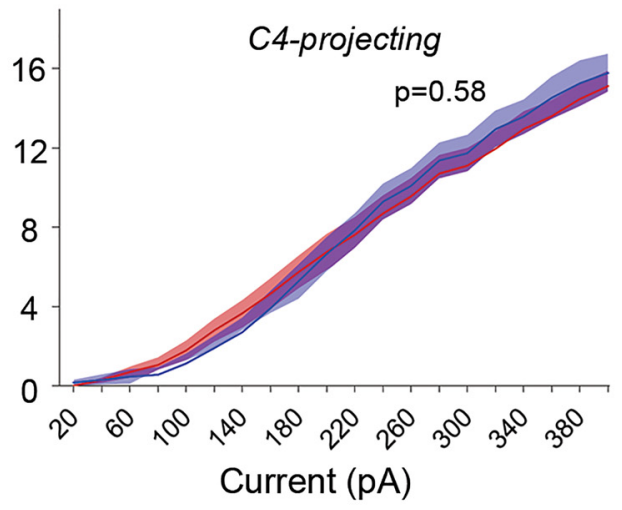

C

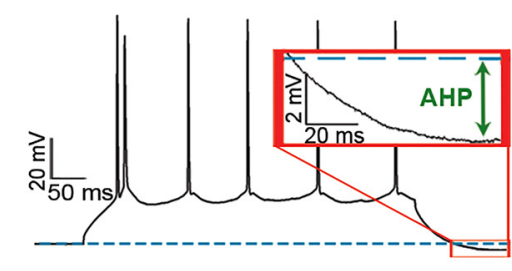

E

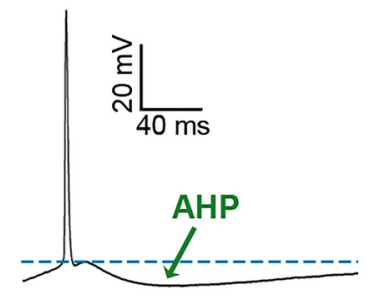

D

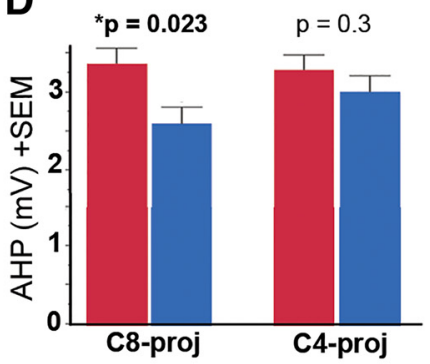

$\mathbf{F}$

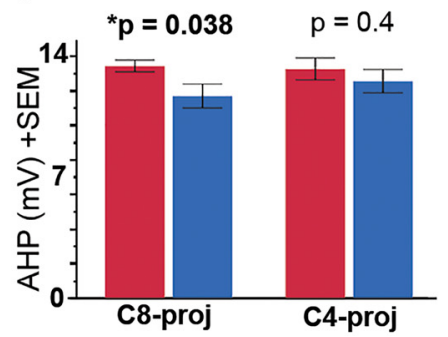

Figure 3. Increased intrinsic neuronal excitability in task-relevant neurons following skilled motor learning. $A$, C8-projecting neurons from trained animals show greater spiking frequency to 500 ms depolarizing current injections compared with (8-projecting cells in untrained animals (repeated-measures ANOVA: $F_{(1,73)}=10.84, p=0.002$ ). $\boldsymbol{B}$, Current-spike relationship did not differ between $\left(4\right.$ trained versus untrained cells $\left(F_{(1,51)}=0.3, p=0.584\right)$. C, Sample corticospinal response to injection of a $300 \mathrm{pA}$ depolarizing square pulse. The afterhyperpolarization (AHP) is measured with respect to predepolarization baseline (dashed blue line). D, AHP values in response to a $300 \mathrm{pA}, 500 \mathrm{~ms}$ current injection are significantly lower in trained animals within the C8-projecting group (two-way ANOVA, $p=0.023$ ). Variables = number of spikes and training condition. Error bars indicate SEM. $E$, AHP was also assessed following a solitary evoked action potential, with AHP amplitude measured with respect to spike threshold. $F$, Using this methodology, AHP was similarly lower in trained animals within the C8-projecting subpopulation ( $t$ test, $\left.t_{(59)}=2.12, p=0.038\right) .{ }^{*} p<0.05$.

Table 2. Neurophysiological properties of C4- and C8-projecting corticospinal populations ${ }^{a}$

\begin{tabular}{|c|c|c|c|c|}
\hline & \multicolumn{2}{|l|}{ C4-projecting } & \multicolumn{2}{|l|}{ C8-projecting } \\
\hline & Untrained $(n>60)$ & Trained $(n>40)$ & Untrained $(n>45)$ & Trained $(n>55)$ \\
\hline Resting $V_{m}(m V)$ & $-67.4 \pm 2.3$ & $-67.6 \pm 2.1 p=0.62$ & $-67.2 \pm 1.8$ & $-67.2 \pm 2.2 p=0.92$ \\
\hline$R_{\text {in }}(M \Omega)$ & $79.6 \pm 20$ & $77 \pm 24 p=0.44$ & $72 \pm 13.5$ & $76.4 \pm 20 p=0.31$ \\
\hline Spike threshold (mV) & $-42.8 \pm 4$ & $-44.3 \pm 4.2 p=0.09$ & $-42.4 \pm 5$ & $-42.9 \pm 4.6 p=0.66$ \\
\hline Rheobase (pA) & $141 \pm 72$ & $146 \pm 56 p=0.7$ & $160 \pm 77$ & $131 \pm 68 p=0.062$ \\
\hline Spike half-width (ms) & $2.32 \pm 0.4$ & $2.38 \pm 0.4 p=0.57$ & $2.26 \pm 0.4$ & $2.36 \pm 0.4 p=0.26$ \\
\hline
\end{tabular}

${ }^{a}$ Data are mean \pm SD. $p$ values reflect comparisons of trained versus untrained conditions within each cell-pair group. For spike threshold, rheobase, spike half-width, and spike height, the membrane holding potential was normalized at $-65 \mathrm{mV}$ across cells via current injection.

exhibited distinct membrane hyperpolarization together with a loss of spontaneous spiking during CNO exposure (Fig. 4C).

Following $10 \mathrm{~d}$ of skilled grasp training, grasping performance was assessed while selectively inhibiting one of these distinct corticospinal subpopulations. Selective inhibition of C8-projecting corticospinal neurons with $\mathrm{CNO}(5 \mathrm{mg} / \mathrm{kg})$ resulted in significant reductions in skilled grasping performance ( $t$ test against $0, t_{(8)}=$ 3.48, $p=0.008$; Fig. $4 D$ ), indicating that these projections are essential in performing skilled grasping. Washout of CNO resulted in complete reversal of the reaching deficit. Conversely, 


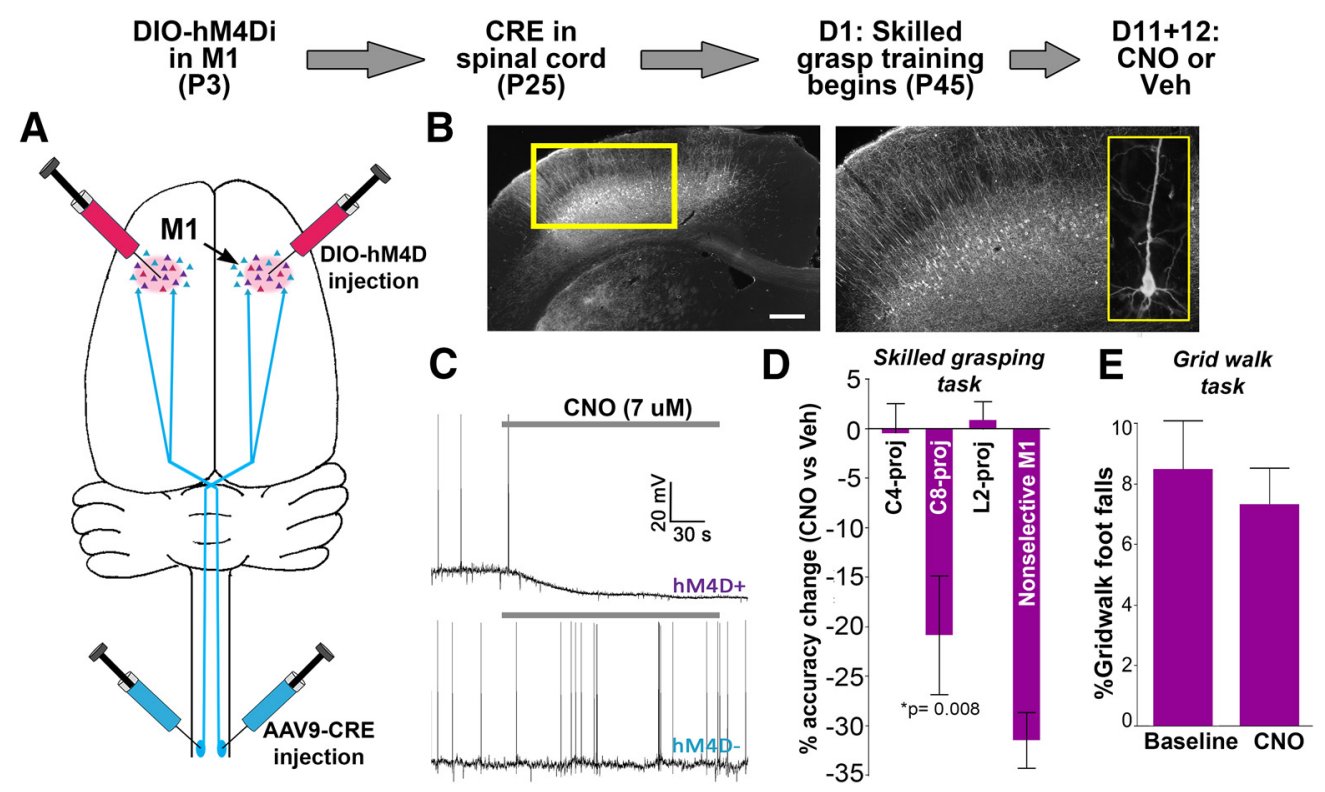

Figure 4. Selective inhibition of (8-projecting corticospinal neurons impairs performance of the learned skilled grasping behavior. Top, Timeline for targeted cell inhibition. $A$, At $3 \mathrm{~d}$ postnatal, injections of cre-dependent virus expressing hM4D(Gi) were targeted to M1. At age $25 \mathrm{~d}$, the same animals received spinal cord injections of cre-expressing virus at one of three spinal cord locations: C8, C4, or L2. B, Cortical expression of hM4D(Gi) was specific to layer 5 motor cortex. Inset, Individual layer 5 pyramidal cell expressing hM4D(Gi). Scale bar, $400 \mu \mathrm{m}$. C, Whole-cell slice recordings demonstrated CN0-induced hyperpolarization $>5 \mathrm{mV}$ in hM4D(Gi)-expressing neurons $(n=5 / 5)$. Neighboring layer 5 neurons not expressing hM4D(Gi) did not show hyperpolarization in the presence of CNO $(n=0 / 5)$. Gray bars represent CNO application. $\boldsymbol{D}$. Animals underwent $10 \mathrm{~d}$ of training on the skilled grasping task, which required animals to retrieve a $45 \mathrm{mg}$ sugar pellet with a single forepaw. Pellet retrieval was impaired in the presence of $\mathrm{CNO}(5 \mathrm{mg} / \mathrm{kg})$ versus vehicle in animals expressing hM4D(Gi) in (8-projecting cells. In contrast, performance was unaffected by CNO in animals with hM4D(Gi) expression in corticospinal neurons largely unrelated to grasping (C4-projecting), or negative control animals with hM4D(Gi) expression in neurons controlling the hind limbs (L2-projecting). Animals receiving injections of non-cre-dependent hM4D(Gi) virus directly into M1 were predictably impaired in the presence of CNO $(n: C 8=9, C 4=7, L 2=5, M 1=2)$. Error bars $=$ SEM. $\boldsymbol{E}$, Unlike the fine motor refinements required for acquisition of the skilled grasping task, the grid walk is an unskilled motor task that does not require training of motor outputs controlled by the motor cortex. Accordingly, inhibition of the (8-projecting corticospinal subpopulation $(n=6 ; \mathrm{CNO}=5 \mathrm{mg} / \mathrm{kg})$ did not impair grid walk performance $(p=0.578)$. Error bars $=\mathrm{SEM}$.

selective inhibition of C4- or lumbar level 2 (L2)-projecting corticospinal subpopulations had no effect on grasping performance (C4: $p=0.927$; L2: $p=0.962$; Fig. $4 D$ ), indicating that these projections are not essential in skilled grasping. We further tested whether the $\mathrm{C} 8$ projection pathway is crucial for an unskilled motor behavior, the grid walk task (Krisa et al., 2012). Selective inhibition of C8-projecting neurons did not impair performance on this test versus baseline (paired $t$ test, $t_{(5)}=0.59, p=0.578$; Fig. $4 E$ ), indicating that gross motor function of the forelimbs remained intact. These findings identify an essential role for C8-projecting corticospinal neurons in the performance of the skilled grasping behavior, and further support that changes in recurrent connectivity preferentially affect the projection subpopulation most relevant for executing the trained motor behavior.

Although hM4D(Gi)-expressing cells were completely silenced in the presence of $\mathrm{CNO}$ ex vivo, it is likely that activity is suppressed, rather than completely silenced, in vivo. This suggests that perturbation of normal network activity may be sufficient to impair motor performance, which is consistent with neurophysiological studies showing that fine motor behavior is associated with precisely coordinated network dynamics (Schieber, 2002; Kargo and Nitz, 2003, 2004; Peters et al., 2014).

\section{Discussion}

Theoretical models suggest that reorganization of recurrent networks exerts a pivotal role in the acquisition, refinement, and stabilization of new motor skills (Alvarez and Squire, 1994; Douglas and Martin, 2007; Laje and Buonomano, 2013). Indeed, motor training is accompanied by modifications in movementrelated firing, neural synchrony, and stabilization of spatiotemporal activity patterns (Schieber, 2002; Kargo and Nitz, 2004; Komiyama et al., 2010; Huber et al., 2012; Masamizu et al., 2014;
Peters et al., 2014), functions that are likely enhanced by modifications in recurrent connectivity. Although evidence indicates that motor training elicits the formation of new synaptic contacts within M1 (Xu et al., 2009; Yang et al., 2009; Hayashi-Takagi et al., 2015), the identity of these synaptic partners and their relationship to the trained behavior are largely unknown. We now show that reorganization of recurrent cortical inputs accompanies the acquisition and stabilization of skilled motor behavior, and that this reorganization is specific to the subpopulation of neurons most relevant for executing the trained behavior. These findings provide specific mechanisms that may contribute to training-associated alterations in neural dynamics. For example, augmented recurrent connectivity across functionally related cells, in conjunction with greater intrinsic excitability, could promote both greater and more synchronous activity of task-related neuronal ensembles (Schieber, 2002; Komiyama et al., 2010; Huber et al., 2012; Peters et al., 2014) while also reducing response variability across trials (Kargo and Nitz, 2004; Peters et al., 2014).

In addition to recurrent connections, layer 5 neurons in M1 receive long-range afferent input from regions, including transcallosal M1, premotor areas, somatosensory cortex, and sensory/motor thalamus (Hooks et al., 2013; Suter and Shepherd, 2015). We have previously shown that skilled grasp training augments the synaptic strength of TC inputs impinging on training-related corticospinal neurons (the TC-C8 pathway) (Biane et al., 2016). Specifically, we found that quantal amplitude (i.e., the postsynaptic response to the release of a single presynaptic vesicle) was selectively increased within the TC-C8 pathway following training. In contrast, the current study suggests that the number of synaptic contacts, and not individual synaptic strength, is augmented in recurrent corticospinal networks following training, demonstrating that synaptic mecha- 
nisms of experience-dependent cortical plasticity vary across different network domains in adulthood, even in response to the same stimulus (skilled grasp training).

While the observed increase in recurrent connectivity could be in part due to an unmasking of latent, or "silent," synaptic connections between C8-projecting neurons, the data do not support this scenario for several reasons. First, presynaptic release probability and uEPSC amplitude did not increase with training, as might be expected if training-related strengthening of synapses contributed to the detection of hidden connections. To further examine this issue, however, we determined the coefficient of variation for uEPSC amplitude (Table 1), which is negatively correlated to release probability. The advantage of this approach is that it includes all stimulation trials and hence does not rely on a potentially arbitrary selection of synaptic failures versus successes. Again, the coefficient of variation was not significantly different before and after training. That training induces an increase in the overall number of recurrent synaptic contacts among C8projecting neurons is further supported by studies demonstrating that spinogenesis in M1 accompanies grasp training (Kleim et al., 2002; Xu et al., 2009; Fu et al., 2012), specifically within the C8projecting subpopulation (Wang et al., 2011). Finally, latent connections in the form of silent synapses are largely absent in the adult rodent cortex (Isaac et al., 1997; Rumpel et al., 1998; Barnes and Finnerty, 2010; Funahashi et al., 2013), indicating that "AMPAfication" of silent synapses is unlikely to have contributed to the increased connectivity reported here following training.

In recent years, plasticity of intrinsic neuronal properties has become increasingly recognized as a prominent mechanism of learning and memory (Titley et al., 2017). Increased intrinsic excitability has been observed following learning across multiple cell types and brain regions (Titley et al., 2017), and enhancing or suppressing intrinsic excitability can facilitate or inhibit behavioral learning, respectively (Deyo et al., 1989; McKay et al., 2012). Such findings have led to a growing sense that the neural basis of learning and memory resides not only at the synaptic level, but also with plasticity spanning the neuronal unit as a whole.

In addition to changes in network connectivity, we also identified an increase in intrinsic excitability specifically within the training-related subpopulation of neurons, as well as a reduction of the medium AHP current. Because intrinsic excitability is augmented in layer 5 motor cortex neurons in an activity-dependent manner (Paz et al., 2009), the observed change in intrinsic excitability may be driven by increased excitatory synaptic input, both local and long-range, which boosts the activity of $\mathrm{C} 8$-projecting neurons. Conversely, it is also possible that heightened excitability is driving the increase in recurrent connectivity. For example, smallconductance calcium-activated potassium (SK) channels, which mediate the medium AHP signal (Lape and Nistri, 2000; Faber and Sah, 2007), have been implicated in dendritic excitability and synaptic plasticity (Faber and Sah, 2007), and may thus enhance the formation of recurrent connections between task-related neurons (Sah and Bekkers, 1996; Daoudal and Debanne, 2003; Silva et al., 2009; Zhou et al., 2009). Questions of whether plasticity of excitability and synaptic input are interdependent, the directionality of these changes, and whether specific synaptic pathways are involved (i.e., local vs long-range) should be explored further.

The present study has sought to identify and characterize experience-dependent changes in recurrent wiring among functionally defined subpopulations in adult mammalian cortex. Whether the observed changes in connectivity are a feature of learning or are induced by the repeated use of trained musculature is unknown. However, motor learning is accompanied by robust spinogenesis in M1 (Kleim et al., 2002; Xu et al., 2009; Yang et al., 2009; Wang et al., 2011; Fu et al., 2012), and unselective ablation of dendritic spines formed during learning impairs subsequent recall of the associated motor memory (HayashiTakagi et al., 2015). On the other hand, increased motor activity in the absence of motor skill learning also augments dendritic spine numbers within $\mathrm{M} 1$, albeit to a significantly lesser extent compared with when such activity is accompanied by learning (Kleim et al., 2002; Wang et al., 2011). Notably, training did not affect connectivity within the C4-projecting subpopulation, which controls upper forelimb musculature that is likewise engaged, but not refined, during training. Nor was connectivity between C4- and C8-projecting cells modified with training. Together, these data indicate that the observed changes within the training-related C8-projecting subpopulation are unlikely to be solely due to activity. Delineating the precise contribution of the observed changes to learning awaits the ability to selectively ablate recurrent synapses forged during training.

In total, the present results demonstrate experience-dependent reorganization of recurrent circuits in the adult motor cortex. Although our examination was confined to layer 5 corticospinal neurons of the motor cortex, theoretical and computational models suggest that targeted reorganization of recurrent networks is likely to be a general property of cortex. Indeed, whiskertrimming paradigms in rodents have shown reorganization of recurrent synaptic circuitry in barrel cortex (Cheetham et al., 2007; Albieri et al., 2015). The extent of which these results further generalize across different cell types and brain regions should be the focus of future experimental inquiry.

\section{References}

Albieri G, Barnes SJ, de Celis Alonso B, Cheetham CE, Edwards CE, Lowe AS, Karunaratne H, Dear JP, Lee KC, Finnerty GT (2015) Rapid bidirectional reorganization of cortical microcircuits. Cereb Cortex 25:30253035 .

Alvarez P, Squire LR (1994) Memory consolidation and the medial temporal lobe: a simple network model. Proc Natl Acad Sci U S A 91:7041-7045.

Anderson CT, Sheets PL, Kiritani T, Shepherd GM (2010) Sublayer-specific microcircuits of corticospinal and corticostriatal neurons in motor cortex. Nat Neurosci 13:739-744.

Barnes SJ, Finnerty GT (2010) Sensory experience and cortical rewiring. Neuroscientist 16:186-198.

Biane JS, Scanziani M, Tuszynski MH, Conner JM (2015) Motor cortex maturation is associated with reductions in recurrent connectivity among functional subpopulations and increases in intrinsic excitability. J Neurosci 35:4719-4728.

Biane JS, Takashima Y, Scanziani M, Conner JM, Tuszynski MH (2016) Thalamocortical projections onto behaviorally relevant neurons exhibit plasticity during adult motor learning. Neuron 89:1173-1179.

Biane J, Conner JM, Tuszynski MH (2014) Nerve growth factor is primarily produced by GABAergic neurons of the adult rat cortex. Front Cell Neurosci $8: 220$.

Binzegger T, Douglas RJ, Martin KA (2004) A quantitative map of the circuit of cat primary visual cortex. J Neurosci 24:8441-8453.

Callister RJ, Brichta AM, Peterson EH (1987) Quantitative analysis of cervical musculature in rats: histochemical composition and motor pool organization: II. Deep dorsal muscles. J Comp Neurol 255:369-385.

Cheetham CE, Hammond MS, Edwards CE, Finnerty GT (2007) Sensory experience alters cortical connectivity and synaptic function site specifically. J Neurosci 27:3456-3465.

Conner JM, Culberson A, Packowski C, Chiba AA, Tuszynski MH (2003) Lesions of the basal forebrain cholinergic system impair task acquisition and abolish cortical plasticity associated with motor skill learning. Neuron 38:819-829.

Conner JM, Chiba AA, Tuszynski MH (2005) The basal forebrain cholinergic system is essential for cortical plasticity and functional recovery following brain injury. Neuron 46:173-179.

Conner JM, Kulczycki M, Tuszynski MH (2010) Unique contributions of 
distinct cholinergic projections to motor cortical plasticity and learning. Cereb Cortex 20:2739-2748.

Daoudal G, Debanne D (2003) Long-term plasticity of intrinsic excitability: learning rules and mechanisms. Learn Mem 10:456-465.

Deyo RA, Straube KT, Disterhoft JF (1989) Nimodipine facilitates associative learning in aging rabbits. Science 243:809-811.

Disterhoft JF, Coulter DA, Alkon DL (1986) Conditioning-specific membrane changes of rabbit hippocampal neurons measured in vitro. Proc Natl Acad Sci U S A 83:2733-2737.

Douglas RJ, Martin KA (2004) Neuronal circuits of the neocortex. Annu Rev Neurosci 27:419-451.

Douglas RJ, Martin KA (2007) Recurrent neuronal circuits in the neocortex. Curr Biol 17:R496-R500.

Douglas RJ, Koch C, Mahowald M, Martin KA, Suarez HH (1995) Recurrent excitation in neocortical circuits. Science 269:981-985.

Faber ES, Sah P (2007) Functions of SK channels in central neurons. Clin Exp Pharmacol Physiol 34:1077-1083.

Fino E, Yuste R (2011) Dense inhibitory connectivity in neocortex. Neuron 69:1188-1203.

Fu M, Yu X, Lu J, Zuo Y (2012) Repetitive motor learning induces coordinated formation of clustered dendritic spines in vivo. Nature 483:92-95.

Funahashi R, Maruyama T, Yoshimura Y, Komatsu Y (2013) Silent synapses persist into adulthood in layer $2 / 3$ pyramidal neurons of visual cortex in dark-reared mice. J Neurophysiol 109:2064-2076.

Gharbawie OA, Whishaw IQ (2006) Parallel stages of learning and recovery of skilled reaching after motor cortex stroke: "oppositions" organize normal and compensatory movements. Behav Brain Res 175:249-262.

Grill R, Murai K, Blesch A, Gage FH, Tuszynski MH (1997) Cellular delivery of neurotrophin-3 promotes corticospinal axonal growth and partial functional recovery after spinal cord injury. J Neurosci 17:5560-5572.

Hayashi-Takagi A, Yagishita S, Nakamura M, Shirai F, Wu YI, Loshbaugh AL, Kuhlman B, Hahn KM, Kasai H (2015) Labelling and optical erasure of synaptic memory traces in the motor cortex. Nature 525:333-338.

Hooks BM, Mao T, Gutnisky DA, Yamawaki N, Svoboda K, Shepherd GM (2013) Organization of cortical and thalamic input to pyramidal neurons in mouse motor cortex. J Neurosci 33:748-760.

Huber D, Gutnisky DA, Peron S, O’Connor DH, Wiegert JS, Tian L, Oertner TG, Looger LL, Svoboda K (2012) Multiple dynamic representations in the motor cortex during sensorimotor learning. Nature 484:473-478.

Isaac JT, Crair MC, Nicoll RA, Malenka RC (1997) Silent synapses during development of thalamocortical inputs. Neuron 18:269-280.

Kargo WJ, Nitz DA (2003) Early skill learning is expressed through selection and tuning of cortically represented muscle synergies. J Neurosci 23:11255-11269.

Kargo WJ, Nitz DA (2004) Improvements in the signal-to-noise ratio of motor cortex cells distinguish early versus late phases of motor skill learning. J Neurosci 24:5560-5569.

Kleim JA, Barbay S, Cooper NR, Hogg TM, Reidel CN, Remple MS, Nudo RJ (2002) Motor learning-dependent synaptogenesis is localized to functionally reorganized motor cortex. Neurobiol Learn Mem 77:63-77.

Ko H, Cossell L, Baragli C, Antolik J, Clopath C, Hofer SB, Mrsic-Flogel TD (2013) The emergence of functional microcircuits in visual cortex. Nature 496:96-100.

Komiyama T, Sato TR, O'Connor DH, Zhang YX, Huber D, Hooks BM, Gabitto M, Svoboda K (2010) Learning-related fine-scale specificity imaged in motor cortex circuits of behaving mice. Nature 464:1182-1186.

Krisa L, Frederick KL, Canver JC, Stackhouse SK, Shumsky JS, Murray M (2012) Amphetamine-enhanced motor training after cervical contusion injury. J Neurotrauma 29:971-989.

Laje R, Buonomano DV (2013) Robust timing and motor patterns by taming chaos in recurrent neural networks. Nat Neurosci 16:925-933.

Lape R, Nistri A (2000) Current and voltage clamp studies of the spike medium afterhyperpolarization of hypoglossal motoneurons in a rat brain stem slice preparation. J Neurophysiol 83:2987-2995.

Li LY, Li YT, Zhou M, Tao HW, Zhang LI (2013a) Intracortical multiplication of thalamocortical signals in mouse auditory cortex. Nat Neurosci 16:1179-1181.

Li YT, Ibrahim LA, Liu BH, Zhang LI, Tao HW (2013b) Linear transformation of thalamocortical input by intracortical excitation. Nat Neurosci $16: 1324-1330$.

Lien AD, Scanziani M (2013) Tuned thalamic excitation is amplified by visual cortical circuits. Nat Neurosci 16:1315-1323.
Markus EJ, Petit TL (1987) Neocortical synaptogenesis, aging, and behavior: lifespan development in the motor-sensory system of the rat. Exp Neurol 96:262-278.

Masamizu Y, Tanaka YR, Tanaka YH, Hira R, Ohkubo F, Kitamura K, Isomura Y, Okada T, Matsuzaki M (2014) Two distinct layer-specific dynamics of cortical ensembles during learning of a motor task. Nat Neurosci 17:987-994.

McKay BM, Oh MM, Galvez R, Burgdorf J, Kroes RA, Weiss C, Adelman JP, Moskal JR, Disterhoft JF (2012) Increasing SK2 channel activity impairs associative learning. J Neurophysiol 108:863-870.

McKenna JE, Prusky GT, Whishaw IQ (2000) Cervical motoneuron topography reflects the proximodistal organization of muscles and movements of the rat forelimb: a retrograde carbocyanine dye analysis. J Comp Neurol 419:286-296.

Morishima M, Morita K, Kubota Y, Kawaguchi Y (2011) Highly differentiated projection-specific cortical subnetworks. J Neurosci 31:1038010391.

Murphy GG, Fedorov NB, Giese KP, Ohno M, Friedman E, Chen R, Silva AJ (2004) Increased neuronal excitability, synaptic plasticity, and learning in aged Kvbetal.1 knockout mice. Curr Biol 14:1907-1915.

Oh MM, Kuo AG, Wu WW, Sametsky EA, Disterhoft JF (2003) Watermaze learning enhances excitability of CA1 pyramidal neurons. J Neurophysiol 90:2171-2179.

Paz JT, Mahon S, Tiret P, Genet S, Delord B, Charpier S (2009) Multiple forms of activity-dependent intrinsic plasticity in layer $\mathrm{V}$ cortical neurones in vivo. J Physiol 587:3189-3205.

Perin R, Berger TK, Markram H (2011) A synaptic organizing principle for cortical neuronal groups. Proc Natl Acad Sci U S A 108:5419-5424.

Peters AJ, Chen SX, Komiyama T (2014) Emergence of reproducible spatiotemporal activity during motor learning. Nature 510:263-267.

Reinhold K, Lien AD, Scanziani M (2015) Distinct recurrent versus afferent dynamics in cortical visual processing. Nat Neurosci 18:1789-1797.

Rumpel S, Hatt H, Gottmann K (1998) Silent synapses in the developing rat visual cortex: evidence for postsynaptic expression of synaptic plasticity. J Neurosci 18:8863-8874.

Sah P, Bekkers JM (1996) Apical dendritic location of slow afterhyperpolarization current in hippocampal pyramidal neurons: implications for the integration of long-term potentiation. J Neurosci 16:4537-4542.

Schieber MH (2002) Training and synchrony in the motor system. J Neurosci 22:5277-5281.

Silva AJ, Zhou Y, Rogerson T, Shobe J, Balaji J (2009) Molecular and cellular approaches to memory allocation in neural circuits. Science 326:391-395.

Song S, Sjöström PJ, Reigl M, Nelson S, Chklovskii DB (2005) Highly nonrandom features of synaptic connectivity in local cortical circuits. PLoS Biol 3:e68.

Suter BA, Shepherd GM (2015) Reciprocal interareal connections to corticospinal neurons in mouse M1 and S2. J Neurosci 35:2959-2974.

Titley HK, Brunel N, Hansel C (2017) Toward a neurocentric view of learning. Neuron 95:19-32.

Tosolini AP, Morris R (2012) Spatial characterization of the motor neuron columns supplying the rat forelimb. Neuroscience 200:19-30.

Urban DJ, Roth BL (2015) DREADDs (designer receptors exclusively activated by designer drugs): chemogenetic tools with therapeutic utility. Annu Rev Pharmacol Toxicol 55:399-417.

Vogels TP, Rajan K, Abbott LF (2005) Neural network dynamics. Annu Rev Neurosci 28:357-376.

Wang L, Conner JM, Rickert J, Tuszynski MH (2011) Structural plasticity within highly specific neuronal populations identifies a unique parcellation of motor learning in the adult brain. Proc Natl Acad Sci U S A 108:2545-2550.

Wang L, Conner JM, Nagahara AH, Tuszynski MH (2016) Rehabilitation drives enhancement of neuronal structure in functionally relevant neuronal subsets. Proc Natl Acad Sci U S A 113:2750-2755.

Xu T, Yu X, Perlik AJ, Tobin WF, Zweig JA, Tennant K, Jones T, Zuo Y (2009) Rapid formation and selective stabilization of synapses for enduring motor memories. Nature 462:915-919.

Yang G, Pan F, Gan WB (2009) Stably maintained dendritic spines are associated with lifelong memories. Nature 462:920-924.

Zhou Y, Won J, Karlsson MG, Zhou M, Rogerson T, Balaji J, Neve R, Poirazi P, Silva AJ (2009) CREB regulates excitability and the allocation of memory to subsets of neurons in the amygdala. Nat Neurosci 12:1438-1443. 